Note

\title{
Effects on Acrylamide Generation under Heating Conditions by Addition of Lysine and Cysteine to Non-centrifugal Cane Sugar
}

\author{
Atsushi Kobayashi ${ }^{1,2^{*}}$, Satoko Gomikawa ${ }^{2}$, Asami Oguro ${ }^{2}$, Satoshi Maeda ${ }^{2}$, Akira Yamazaki ${ }^{2}$, Shinji Sato \\ and Hirofumi MaEKAWA ${ }^{1}$ \\ ${ }^{1}$ Nagaoka University of Technology, Kamitomioka-machi, Nagaoka, Niigata 940-2188, Japan \\ ${ }^{2}$ Research Institute, Echigoseika Co., Ltd., Takanashi-machi, Ojiya, Niigata 947-0193, Japan \\ ${ }^{3}$ Laboratory of Functional and Analytical Food Science, Niigata University of Pharmacy and Applied Life Science, \\ Higashijima, Akiha-ku, Niigata, Niigata 956-8603, Japan
}

Received December 26, 2019 ; Accepted June 17, 2020

We investigated the effects on acrylamide generation under heating conditions by addition of lysine and cysteine using non-centrifugal cane sugar (NCS) aqueous solutions as food models. The four NCS samples tested contained relatively high concentrations of acrylamide. Treating an aqueous solution of NCS at $100{ }^{\circ} \mathrm{C}$ for $60 \mathrm{~min}$ significantly increased the amount of acrylamide. We determined the concentrations of reducing sugar and free amino acids in the NCS samples and in NCS-related products and confirmed that all contained large amounts of reducing sugar and asparagine, which are major acrylamide reactants. Adding cysteine to an NCS solution suppressed the amount of acrylamide formed by heating at $100{ }^{\circ} \mathrm{C}$ for $60 \mathrm{~min}$, whereas adding lysine promoted it. These amino acids dose-dependently affected acrylamide generation. Moreover, adding cysteine to NCS solutions suppressed the generation of acrylamide over a wide range of $\mathrm{pH}$ values. These findings suggest a method for preventing the generation of acrylamide during food processing.

Keywords: acrylamide, non-centrifugal cane sugar, lysine, cysteine

\section{Introduction}

Acrylamide, a potential human carcinogen, is produced when carbohydrate-rich foods and ingredients are processed at temperatures above $120{ }^{\circ} \mathrm{C}$ (Tareke et al., 2002). Consequently, many researchers worldwide have measured acrylamide levels in processed foods and devised methods for its reduction (Becalski et al., 2004; Granda et al., 2004; Pedreschi et al., 2004; Baardseth et al., 2006; Rommens et al., 2008; Kukurová et al., 2009; Zeng et al., 2009; Cheng et al., 2010; Palazoğlu et al., 2010). In Japan, the Ministry of Agriculture, Forestry and Fisheries has stated that research on acrylamide in food products is an important issue for the food industry and published a "guideline for reducing acrylamide in foods" for food-related businesses in November 2013 (i). Strategies for decreasing acrylamide in heat-processed foods have received much attention both domestically and internationally in an effort to safeguard human health. However, decreasing acrylamide levels by decreasing the temperature used to process foods is complicated because heat processing kills microorganisms, thus decreasing the likelihood of food poisoning, and improves the aroma, color, and texture of foods. Aromas and colors are enhanced during the Maillard reaction, which is also the main reaction that generates acrylamide (Katayama and Tajima, 2003; Shimizu, 2004). For example, acrylamide is formed early during the Maillard reaction when asparagine is heated above $120{ }^{\circ} \mathrm{C}$ in the presence of reducing sugars (Tareke, et al., 2002). As the palatability and safety of foods are clearly of paramount importance to the food industry, methods for controlling the Maillard reaction are required to ensure production of the highest quality products. 
Non-centrifugal cane sugar (NCS) is traditionally manufactured by evaporating water from sugarcane juice without centrifugation. The product is variously called muscovado, panela, and kokuto (Jaffé, 2012; Jaffé, 2015). NCS has a distinctive sweet aroma and a sweet and rich flavor, and is used for a variety of processed foods such as confectioneries. The distinctive aroma and dark color that characterize NCS are generated during heat treatment processes in the manufacture of NCS (Tokitomo et al., 1984; Okumura, 1993). NCS contains functional antioxidants, some of which are generated during the Maillard reaction occurring during heat processing (Yamaguchi and Yamada, 1981; Takara et al., 2007). Unfortunately, acrylamide is formed simultaneously and accumulates in NCS (ii). Moreover, processed foods made with NCS may accumulate additional acrylamide during heat processing because NCS contains reactants that give rise to acrylamide, such as reducing sugars and amino acids derived from sugarcane (iii, Nakasone et al., 1990). The food industry therefore requires a method for inhibiting acrylamide formation in susceptible food ingredients, such as NCS.

The purpose of this study was to investigate approaches for suppressing acrylamide formation in processed foods. We previously used aqueous model systems and reported that the acrylamide content in foods could be reduced by heat treatment with lysine and cysteine below $120^{\circ} \mathrm{C}$ (Kobayashi et al., 2014). Here, we report the inhibition of acrylamide generation by treating NCS aqueous solutions with lysine and cysteine.

\section{Materials and Methods}

Materials Acrylamide (ultra-pure, $>99.9 \%$ ) was purchased from Kanto Chemical (Tokyo, Japan) and ${ }^{13} \mathrm{C}_{1^{-}}$ labelled acrylamide ( $>98 \%$ ) for use as an internal standard (IS) was from CDN Isotopes (Montreal, Quebec, Canada). All other chemicals were of analytical grade and were purchased from Wako Pure Chemical Industries (Osaka, Japan). Water used for all reactions was purified using an Auto Pure WT101 UV apparatus from Yamato Scientific (Tokyo, Japan).

Four NCSs (NCS A, B, C, and D), and one sample each of molasses, brown sugar syrup (syrup) and brown sugar, were commercial products. NCS A and D were obtained from Sanko Shokuhin (Tokyo, Japan), NCS B and C from Mitsubishi Corporation Life Sciences Limited (Tokyo, Japan), molasses and syrup from Morita Food System (Mie, Japan), brown sugar from Miyoshi (Osaka, Japan). Acrylamide levels of the four NCSs were quantified. The levels of reducing sugars and free amino acids were quantified in all seven samples. All samples were stored at room temperature until use.

Quantification of acrylamide in NCS by liquid chromatographytandem mass spectrometry (LC-MS/MS) Acrylamide was extracted and purified as previously reported (Kobayashi et al., 2019) using a modification of the method described by Delatour et al. (2004). Each NCS sample was homogenized in a mortar, then a $2 \mathrm{~g}$ aliquot was placed in a $30-\mathrm{mL}$ polypropylene centrifuge tube and ${ }^{13} \mathrm{C}_{1}$-acrylamide $(20 \mu \mathrm{L}$ of $100 \mu \mathrm{g} / \mathrm{mL})$ was added as the IS. Water $(10 \mathrm{~mL})$ was added and the tube was shaken vigorously until the NCS dissolved completely. Carrez I reagent [15\% potassium hexacyanoferrate (II) trihydrate solution, wt/vol; $1 \mathrm{~mL}]$ and $1 \mathrm{~mL}$ of Carrez II reagent ( $30 \%$ zinc sulfate heptahydrate solution, wt/vol) were added and the tube was immediately shaken. The mixture was centrifuged at $15000 \times \mathrm{g}$ at $10{ }^{\circ} \mathrm{C}$ for $20 \mathrm{~min}$ and the supernatant $(5 \mathrm{~mL})$ was transferred into a $30-\mathrm{mL}$ glass centrifuge tube containing sodium chloride $(1.5 \mathrm{~g})$. The tube was shaken until the sodium chloride completely dissolved, then $10 \mathrm{~mL}$ of ethyl acetate was added and the suspension was shaken vigorously for $1 \mathrm{~min}$. The suspension was centrifuged at $1100 \times g$ at room temperature for $10 \mathrm{~min}$ (himac CT-15D, Hitachi Koki, Tokyo, Japan) to separate the phases and the organic phase was transferred into a $100-\mathrm{mL}$ evaporating flask. The aqueous phase was further extracted twice with ethyl acetate $(2 \times 10 \mathrm{~mL})$ and the combined organic extract (approx. $30 \mathrm{~mL}$ ) was evaporated with a rotary evaporator (Tokyo Rikakikai, Tokyo, Japan) at $40{ }^{\circ} \mathrm{C}$ and the residue dissolved in $2 \mathrm{~mL}$ of water. This sample was loaded onto a preconditioned $500 \mathrm{mg}$-Isolute Multimode cartridge $(3 \mathrm{~mL}$ of methanol and $6 \mathrm{~mL}$ of water, International Sorbet Technology, Glamorgan, United Kingdom) and the eluate was collected in a $10-\mathrm{mL}$ glass vial. Water $(1 \mathrm{~mL})$ was loaded onto the cartridge and the two eluates were combined and concentrated to $500 \mu \mathrm{L}$ under a gentle stream of nitrogen in a temperature-controlled water bath at $40{ }^{\circ} \mathrm{C}$, then filtered through a filter unit $(0.20-\mu \mathrm{m}$ pore size). The filtrate was frozen and stored at $-18{ }^{\circ} \mathrm{C}$ until analysis.

Acrylamide was analyzed on a LCMS-8030A (Shimadzu, Kyoto, Japan) as described by Kobayashi et al. (2019). The purified samples were separated on a reverse-phase $\mathrm{C} 18$ column (Synergi Hydro-RP, $250 \mathrm{~mm} \times 2 \mathrm{~mm}$ i.d., $4 \mu \mathrm{m}$, Phenomenex, Torrance, CA, USA) at an oven temperature of $40{ }^{\circ} \mathrm{C}$. The sample injection volume was $10 \mu \mathrm{L}$. LC separation was performed using an isocratic mobile phase of methanol and $0.1 \mathrm{vol} \%$ acetic acid $(2: 98, \mathrm{v} / \mathrm{v})$ at a flow rate of $0.2 \mathrm{~mL} /$ min. The eluted acrylamide was ionized using positive electrospray ionization mode (ESI+). The ESI source was operated as follows: nebulizer gas (nitrogen) flow rate, $3.0 \mathrm{~L} /$ min; interface voltage, $4.5 \mathrm{kV}$; DL temperature, $250{ }^{\circ} \mathrm{C}$; block heater temperature, $400{ }^{\circ} \mathrm{C}$; drying gas flow, $15 \mathrm{~L} / \mathrm{min}$; CID gas, $230 \mathrm{kPa}$; detector voltage, $1.74 \mathrm{kV}$. Acrylamide and IS were detected and identified in multiple reaction monitoring $(\mathrm{MRM})$ mode at $m / z 72.10>54.95$ and $\mathrm{m} / z 73.10>55.95$, respectively. The acrylamide concentration was quantified using a standard curve prepared from the peak area ratio of acrylamide $(0-1000 \mathrm{ng} / \mathrm{mL})$ to IS $(1000 \mathrm{ng} / \mathrm{mL})$. All analyses were performed in triplicate and the results are expressed as means $\pm \mathrm{SD}$. The limit of detection and the limit of quantification of acrylamide (at signal-to-noise ratios of 3 and 10), depending on contamination of the ion source, were $5 \mathrm{ng} / \mathrm{mL}$ and $15 \mathrm{ng} /$ $\mathrm{mL}$, respectively. 
Quantification of reducing sugars in NCS The amount of reducing sugar in NCS was determined by the Somogyi-Nelson method (Somogyi, 1952; Nelson, 1944). A $0.25 \mathrm{~g}$ portion of NCS or brown sugar was dissolved in water and brought to $25 \mathrm{~mL}$. A $0.5 \mathrm{~g}$ portion of molasses or syrup was dissolved in water and brought to $25 \mathrm{~mL}$. The sample solution was diluted with water to the appropriate concentration. Glucose was used as a standard and the results were expressed as milligrams of reducing sugar equivalent per $100 \mathrm{~g}$ of NCS, molasses or syrup.

Quantification of amino acids in NCS Sample (1 g) was added to a $15-\mathrm{mL}$ polypropylene tube and dissolved in $2 \mathrm{~mL}$ of water. The solution was brought to $10 \mathrm{~mL}$ with ethanol, stirred vigorously, then centrifuged at $1100 \times g$ for $20 \mathrm{~min}$. The supernatant $(5 \mathrm{~mL})$ was transferred to a 100 -mL evaporating flask and evaporated at $40{ }^{\circ} \mathrm{C}$. The residue was dissolved in $\mathrm{pH}$ 2.2 lithium citrate buffer solution, brought to $10 \mathrm{~mL}$ in a measuring flask, filtered through a filter unit $(0.45-\mu \mathrm{m}$ pore size), and stored at $5{ }^{\circ} \mathrm{C}$ until analysis.

Samples were analyzed on an amino acid analysis system (Shimadzu). The samples (injection volume: $10 \mu \mathrm{L}$ ) were separated on a Shim-pack Amino-Li column $(100 \mathrm{~mm} \times 6 \mathrm{~mm}$ i.d., Shimadzu GLC, Kyoto, Japan) with a pre-column (Shimpack ISC-30/S0504Li, $50 \mathrm{~mm} \times 4 \mathrm{~mm}$ i.d., Shimadzu GLC). A standard solution was prepared by mixing ${ }_{\mathrm{L}}$-asparagine with amino acids mixture standard solutions Type AN-2 and B (Wako Pure Chemical Industries, Osaka, Japan).

Acrylamide generation in amino acid-containing NCS solution We found that NCS D contained the highest acrylamide content in the four NCS samples tested and thus we examined the suppression of acrylamide generation by lysine or cysteine using NCS D aqueous solutions as food models. To a $15-\mathrm{mL}$ polypropylene centrifuge tube, a $2 \mathrm{~g}$ portion of homogenized NCS D was added, then $1.5 \mathrm{~mL}$ of water was added and the NCS was dissolved by swirling. Amino acid solution (20 or $100 \mathrm{mM}$; $0.5 \mathrm{~mL}$ ) was added to a final concentration of 5 or $25 \mathrm{mmol} / \mathrm{kg}$ NCS. The amino acid solution was replaced with water in the controls. Each tube was capped and heated in an oil bath at 60 or $100{ }^{\circ} \mathrm{C}$ for $60 \mathrm{~min}$, then the tube was immediately cooled in ice water for $15 \mathrm{~min}$ to stop further reaction. Each sample was diluted with water to the proper concentration as needed, then a $10 \mathrm{~mL}$ portion was placed in a $30-\mathrm{mL}$ polypropylene centrifuge tube, ${ }^{13} \mathrm{C}_{1}$-acrylamide $(20 \mu \mathrm{L}$ of $100 \mu \mathrm{g} / \mathrm{mL})$ was added as an IS, and the mixture was stirred. The effect of the added amino acid was assayed as described above in Quantification of acrylamide in NCS by LC$M S / M S$.

The effect of cysteine on acrylamide generation in $\mathrm{pH}$ adjusted NCS solution To a $15-\mathrm{mL}$ polypropylene centrifuge tube, a $2 \mathrm{~g}$ portion of homogenized NCS was added, and a total of $1.5 \mathrm{~mL}$ of acid or base $(0.5 \mathrm{M} \mathrm{HCl}$ or $\mathrm{NaOH})$ and water were added to the sample to adjust the $\mathrm{pH}$ and the NCS was dissolved by swirling. Amino acid solution $(100 \mathrm{mM} ; 0.5 \mathrm{~mL})$ was added to provide a final concentration of $25 \mathrm{mmol} / \mathrm{kg} \mathrm{NCS}$.
The amino acid solution was replaced with water for the controls. Each tube was capped and heated in the oil bath at $100{ }^{\circ} \mathrm{C}$ for $60 \mathrm{~min}$. Subsequent procedures were as described above in Acrylamide generation in amino acid-containing NCS solution.

pH measurement of treated samples The $\mathrm{pH}$ values of the samples were measured with a $\mathrm{pH}$ meter (Horiba, Kyoto, Japan) equipped with a glass electrode.

Statistical analysis Statistical analysis was performed using Welch's $t$-test in Microsoft Excel 2013 and a statistically significant difference was defined as $p<0.05$.

\section{Results}

Quantitation of acrylamide in NCS Table 1 shows the acrylamide concentration of the four NCS samples as determined by LC/MS/MS analysis. The acrylamide concentration ranged from 0.13 to $0.48 \mathrm{mg} / \mathrm{kg}$, with the highest concentration being in NCS D. NCS D was thus chosen as a food model to investigate the reduction of acrylamide by amino acids.

Reducing sugar and amino acid concentrations in NCS and related products Table 2 shows the concentrations of reducing sugar and amino acids in the four NCSs and three related products (molasses, syrup, and brown sugar). The concentration of reducing sugar ranged from 1.6 to $35.2 \mathrm{~g} / 100 \mathrm{~g}$, with molasses having the highest value. Asparagine was a major free amino acid in five of the seven samples and ranged from 2.4 to $307.4 \mathrm{mg} / 100 \mathrm{~g}$. The proportion of asparagine to total free amino acids ranged from 22.9 to $68.8 \%$, with NCS A having the highest amount and proportion of asparagine. It should be noted that asparagine was not separated from glutamic acid in NCS B, D, and in syrup. We estimated that the concentration of asparagine was higher than that of glutamic acid. Hirose and coworkers (2015) measured free amino acid content in brown sugar, the ratio of glutamic acid and asparagine in their sample was almost the same as ours.

The amount of acrylamide generated in amino acidcontaining NCS solution Table 3 shows the concentration of acrylamide in amino acid-containing NCS D solutions treated at 60 or $100{ }^{\circ} \mathrm{C}$ for $60 \mathrm{~min}$. In the controls (no amino acid added), there was essentially no difference in the acrylamide concentration of the NCS D solution before or after heating at $60{ }^{\circ} \mathrm{C}$, whereas treatment at $100{ }^{\circ} \mathrm{C}$ resulted in about 7 -fold

Table 1. Acrylamide concentrations of the NCS samples.

\begin{tabular}{cc}
\hline Sample & $\begin{array}{c}\text { Acrylamide content } \\
(\mathrm{mg} / \mathrm{kg})\end{array}$ \\
\hline NCS A & $0.16 \pm 0.01$ \\
NCS B & $0.30 \pm 0.00$ \\
NCS C & $0.13 \pm 0.00$ \\
NCS D & $0.48 \pm 0.01$ \\
\hline
\end{tabular}

NCS: non-centrifugal cane sugar. Mean $\pm \operatorname{SD}(n=3)$. 
Table 2. Reducing sugar and free amino acid concentrations of the NCSs and cane sugar-related products tested (per $100 \mathrm{~g}$ ).

\begin{tabular}{|c|c|c|c|c|c|c|c|}
\hline & & & & & Molasses & Syrup & Brown sugar \\
\hline & A & B & $\mathrm{C}$ & $\mathrm{D}$ & & & \\
\hline Reducing sugar (g) & 2.9 & 2.9 & 1.6 & 4.1 & 35.2 & 14.6 & 2.0 \\
\hline Amino acid (mg) & 446.6 & 161.3 & 6.1 & 240.7 & 20.5 & 399.9 & 26.8 \\
\hline Tau & 1.3 & 4.0 & 0.0 & 0.0 & 0.0 & 2.5 & 0.0 \\
\hline Asp & 49.3 & 27.4 & 2.7 & 33.8 & 8.5 & 74.5 & 5.6 \\
\hline Thr & 3.1 & 1.7 & 0.0 & 2.0 & 0.0 & 2.3 & 0.0 \\
\hline Ser & 11.6 & 3.2 & 0.2 & 4.0 & 0.2 & 7.8 & 0.4 \\
\hline Asn & 307.4 & $92.1 *$ & 2.4 & $148.2 *$ & 4.7 & $251.4 *$ & 13.7 \\
\hline Glu & 22.4 & $5.9^{*}$ & 0.3 & $9.5^{*}$ & 0.0 & $16.0^{*}$ & 0.6 \\
\hline Gly & 2.1 & 0.5 & 0.0 & 1.8 & 0.1 & 2.5 & 0.2 \\
\hline Ala & 24.6 & 8.0 & 0.4 & 19.3 & 3.5 & 17.3 & 2.8 \\
\hline Val & 6.8 & 8.0 & 0.2 & 10.8 & 2.1 & 8.7 & 1.6 \\
\hline Cys & 0.0 & 0.0 & 0.0 & 0.0 & 0.0 & 0.0 & 0.0 \\
\hline Met & 0.0 & 0.0 & 0.0 & 0.0 & 0.0 & 0.0 & 0.0 \\
\hline Ile & 3.4 & 4.5 & 0.0 & 4.4 & 0.5 & 4.9 & 0.5 \\
\hline Leu & 2.1 & 0.0 & 0.0 & 1.5 & 0.3 & 1.8 & 0.3 \\
\hline Tyr & 2.2 & 1.1 & 0.0 & 1.7 & 0.4 & 2.5 & 0.4 \\
\hline Phe & 2.0 & 0.7 & 0.0 & 0.9 & 0.0 & 2.3 & 0.3 \\
\hline$\beta$-Ala & 0.9 & 3.0 & 0.0 & 1.0 & 0.0 & 1.4 & 0.0 \\
\hline GABA & 7.6 & 1.4 & 0.0 & 1.7 & 0.2 & 3.8 & 0.4 \\
\hline His & 0.0 & 0.0 & 0.0 & 0.0 & 0.0 & 0.0 & 0.0 \\
\hline 3-Methyl His & 0.7 & 0.0 & 0.0 & 0.0 & 0.0 & 0.3 & 0.0 \\
\hline Lys & 0.0 & 0.0 & 0.0 & 0.0 & 0.0 & 0.0 & 0.0 \\
\hline Arg & 0.0 & 0.0 & 0.0 & 0.0 & 0.0 & 0.0 & 0.0 \\
\hline
\end{tabular}

NCS: non-centrifugal cane sugar.

*Glu wasn't separated from Asn. The concentration of Glu was calculated from the ratio of Glu to Asn that was 6 to 94 in brown sugar reported by Hirose et al. (2015).

Table 3. Effect of adding the amino acids lysine or cysteine to NCS D, followed by heating for $60 \mathrm{~min}$

\begin{tabular}{c|l|cc|cc}
\hline \multirow{2}{*}{$\begin{array}{c}\text { Heating temp. } \\
\left({ }^{\circ} \mathrm{C}\right)\end{array}$} & \multicolumn{4}{|c}{ Acrylamide content $(\mathrm{mg} / \mathrm{kg})$} \\
\cline { 2 - 6 } & no amino acid & \multicolumn{2}{|c}{ Lys } & \multicolumn{2}{c}{ Cys } \\
\hline \multirow{2}{*}{$\begin{array}{c}\text { No treatment } \\
60\end{array}$} & $0.30 \pm 0.02$ & - & - & - & - \\
100 & $0.32 \pm 0.01$ & $0.38 \pm 0.00^{*}$ & $0.43 \pm 0.03 *$ & $0.36 \pm 0.03$ & $0.30 \pm 0.02$ \\
& $2.11 \pm 0.16 * *$ & $2.40 \pm 0.10^{*}$ & $3.71 \pm 0.04 *$ & $2.08 \pm 0.08$ & $1.20 \pm 0.02 *$ \\
\hline
\end{tabular}

*Cys- or Lys-added NCS D was significantly different from non-amino acid NCS D; **non-amino acid NCS D was significantly different from untreated. Data were analyzed using Welch's $t$ test $(p<0.05)$. NCS: non-centrifugal cane sugar. Mean $\pm \mathrm{SD}(\mathrm{n}=3 \sim 15)$.

higher acrylamide concentration compared to prior to heating. The addition of either 5 or $25 \mathrm{mmol} / \mathrm{kg}$ lysine to NCS D solution enhanced the increase in acrylamide concentration at both 60 and $100{ }^{\circ} \mathrm{C}$. In particular, the addition of $25 \mathrm{mmol} / \mathrm{kg}$ lysine, followed by $100{ }^{\circ} \mathrm{C}$ for $60 \mathrm{~min}$, resulted in a 1.8 -fold higher acrylamide concentration compared to the control treated at the same temperature. In contrast, adding $25 \mathrm{mmol} /$ $\mathrm{kg}$ cysteine to the NCS D solution suppressed the generation of acrylamide at $100{ }^{\circ} \mathrm{C}$ : the acrylamide concentration was 0.6 -fold lower than that of the control at the same temperature. The effect of both amino acids showed dose dependency. It should be noted that different production lots of NCS D resulted in different measured concentrations, as shown in Tables 1 and 3 .

The effect of cysteine on acrylamide in pH-adjusted NCS solutions Based on the above results, we determined the acrylamide concentrations of $\mathrm{pH}$-adjusted NCS D solutions 


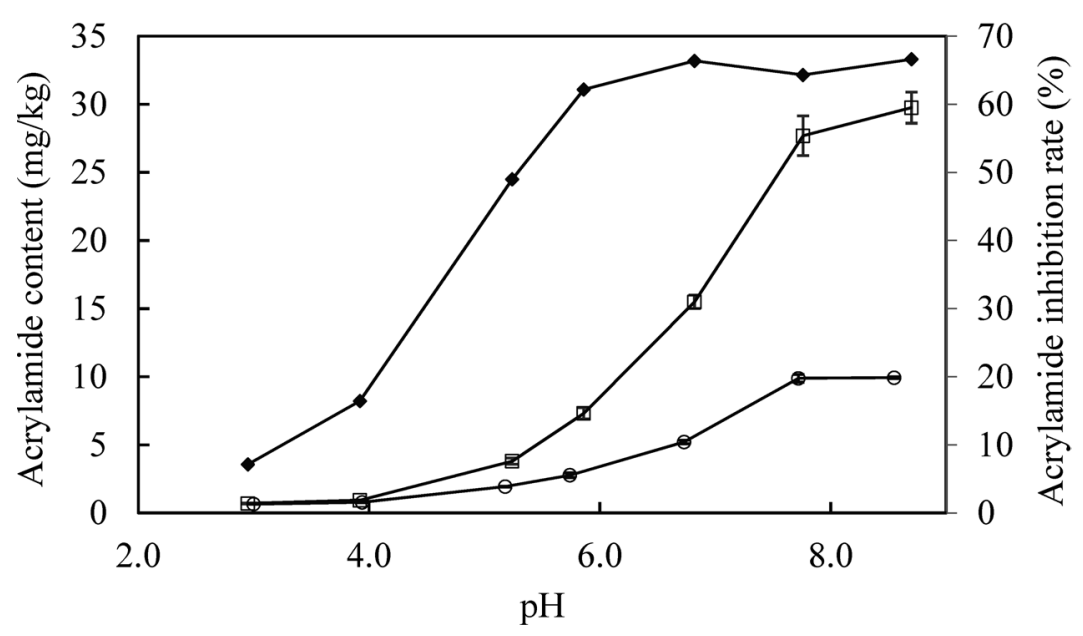

Fig. 1. Effect of $\mathrm{pH}$ on the formation of acrylamide in NCS D solution by heating at $100{ }^{\circ} \mathrm{C}$ for $60 \mathrm{~min}$. Untreated NCS D contained $0.48 \mathrm{mg} / \mathrm{kg}$ acrylamide. $\mathrm{pH}$ values represent the initial $\mathrm{pH}$ of the NCS D solution prior to heating. Symbols represent control $(\square), 25 \mathrm{mmol} / \mathrm{kg}$ Cys containing NCS D $(\bigcirc)$ and acrylamide inhibition rate $(\bullet)$.

NCS: non-centrifugal cane sugar. Mean \pm SD ( $n=3)$.

after treatment at $100{ }^{\circ} \mathrm{C}$ for $60 \mathrm{~min}$ to evaluate the influence of $\mathrm{pH}$ on the ability of cysteine to suppress acrylamide generation. As shown in Fig. 1, the acrylamide concentrations of all NCS D solutions were higher after heating ( 0.65 to $29.8 \mathrm{mg} / \mathrm{kg}$ vs. $0.48 \mathrm{mg} / \mathrm{kg}$ before heating). The amount of acrylamide generated increased with increasing $\mathrm{pH}$ of the NCS D solution before heating. The acrylamide levels of cysteine-containing NCS D solutions were lower than that of the controls, and acrylamide suppression by cysteine was particularly effective at $\mathrm{pH} 6.0$ or higher.

\section{Discussion}

We attempted to suppress the generation of acrylamide in NCS solution containing acrylamide and its reactants using lysine or cysteine. It is noted that the experiment was conducted with a large excess of added amino acids.

As shown in Table 1, all NCSs contained considerable amounts of acrylamide (up to $0.48 \mathrm{mg} / \mathrm{kg}$ ). This result agrees with a report (iv) describing that NCS and NCS-containing processed foods contain significant amounts of acrylamide, indicating that acrylamide is generated during NCS manufacturing processes. In addition, as shown in Table 2, all NCSs and NCS-related products contained notable amounts of reducing sugar and amino acids (particularly asparagine), Jaffé (2015) reported that sucrose is the main component between 76.55 and $89.48 \%$ in NCS. NCSs and NCS-related products we used will also consist largely of sucrose.

This result indicates that heat-processed foods containing NCS contain both acrylamide derived from NCS and acrylamide generated from reducing sugars and asparagine contained in the NCS during their manufacturing processes.

As shown in Table 3, heat treatment at $100{ }^{\circ} \mathrm{C}$ for $60 \mathrm{~min}$ increased the acrylamide concentration of the NCS solution, which is at odds with the widely held belief that acrylamide is formed in foods heated at $120{ }^{\circ} \mathrm{C}$ or higher. Becalski and coworkers (2011) demonstrated that acrylamide was not generated in simulated prune juice consisting of asparagine, sugars, sorbitol, and organic acids under 'wet conditions' in a closed vessel at $120^{\circ} \mathrm{C}$ for 60 min whereas the acrylamide concentration doubled in authentic prune juice under the same conditions. This finding indicates that acrylamide generation is difficult in a simple composition model but is easy in commercially available foods under high moisture at $120{ }^{\circ} \mathrm{C}$ or below. Therefore, the mechanism underlying acrylamide generation in commercially available foods is complex and involves both acrylamide reactants and other food components. Based on these results, we speculate about why acrylamide is easily generated in the NCS solution heated at $100{ }^{\circ} \mathrm{C}$ for 60 min as follows. (1) Production from acrylamide adducts: acrylamide generated during the manufacture of NCS would apparently decrease by forming adducts with other compounds during storage, and then be released when the NCS is reheated. Acrylamide in NCS decreases exponentially soon after NCS production (ii). Acrylamide can react with nucleophiles, including amino acids, via a Michael addition reaction (Adams et al., 2010). The Michael addition reaction between acrylamide and amino compounds is reversible, and acrylamide is generated from its Michael adduct by thermal decomposition (Zamora et al., 2010). These reports support the idea that "hidden" acrylamide-forming adducts in NCS release acrylamide upon heating. (2) Conversion from acrylamide intermediates: NCS may contain comparatively stable intermediates, such as decarboxylated Amadori products and 3-aminopropionamide, which can be converted to acrylamide by heating (Zyzak et al., 2003; Granvogl et al., 2004; Stadler et al., 2004; Granvogl and Schieberle, 2006) In addition, catalysts 
could exist, promoting acrylamide formation. For example, chlorogenic acid catalyzes acrylamide formation by decreasing the activation energy for converting 3-aminopropionamide to acrylamide (Cai et al., 2014). (3) Reaction of asparagine with highly active reactants: highly reactive carbonyl compounds, such as 2-hydroxybutanal, hydroxyacetone and 3-deoxyglucosone derived from sugarcane and generated through the Maillard reaction during NCS production, might react with asparagine to form acrylamide (Stadler et al., 2004; Blank et al., 2005; Ehling et al., 2005; Ishihara et al., 2005; Tsutsumiuchi et al., 2005). In summary, it is likely that acrylamide generation in NCS is intricately influenced by coexisting components of NCS.

We found that amino acids affected the generation of acrylamide in NCS solution, with cysteine suppressing acrylamide formation and lysine promoting it. Our findings are in contrast to earlier reports that both lysine and cysteine inhibit the formation of acrylamide (Claeys et al., 2005; Kim et al., 2005; De Vleeschouwer et al., 2006). Several studies using amino acid-containing model systems have suggested that amino acids reduce the formation of acrylamide. Rydberg and coworkers (2003) reported that the addition of amino acids other than asparagine to homogenized potatoes reduces acrylamide formation markedly and suggested that the added amino acids competitively consume precursors and/or increase acrylamide elimination. Claeys and coworkers (2005) studied the effect of amino acids other than asparagine on acrylamide formation/elimination kinetics using an asparagine-glucose model system and found that adding cysteine or lysine reduces the yield of acrylamide. They reported that lysine appears to function as a competitor of asparagine for sugars in the Maillard reaction whereas cysteine seems to reduce yield by bond-formation with acrylamide (Claeys et al., 2005). We previously reported the elimination of acrylamide by the formation of amino acid adducts, with cysteine reacting with acrylamide over a wide range of $\mathrm{pH}$ values and lysine reacting with acrylamide at alkaline $\mathrm{pH}$ (Kobayashi et al., 2014). In the present study, the $\mathrm{pH}$ value of NCS solution including cysteine or lysine was measured before heating, and the results were 5.1-5.2 and 5.3-5.8, respectively. Thus, we inferred that cysteine reduced acrylamide concentrations by forming an adduct, whereas lysine did not form an adduct, leading to no reduction in acrylamide levels. It was considered that lysine did not react competitively with asparagine.

Cysteine inhibition of acrylamide formation was observed in NCS solutions adjusted to a wide range of $\mathrm{pH}$ values, in agreement with other studies in which the formation and elimination of acrylamide was strongly dependent on the solution pH (Rydberg et al., 2003; De Vleeschouwer et al., 2006). Our demonstration that low $\mathrm{pH}$ efficiently suppresses acrylamide generation in NCS solutions agrees with reports using low pH-adjusted potato models (Rydberg et al., 2003; Mestdagh et al., 2008). In summary, adding cysteine to non- acidic foods may suppress acrylamide generation. It was suggested that extracting acrylamide from foods under high $\mathrm{pH}$ conditions would release extra acrylamide from the food matrix and that this acrylamide is probably formed by Maillard reaction intermediates (JECFA, 2011). A similar mechanism might explain our results using NCS, and cysteine might prevent the formation of intermediate-derived acrylamide at high $\mathrm{pH}$.

\section{Conclusion}

NCS contains acrylamide and reactants such as asparagine and reducing sugars. Acrylamide content in NCS solutions increased by heating at temperatures below $100{ }^{\circ} \mathrm{C}$. These results indicate that the formation of acrylamide in NCS is also influenced by its components except for reactants, such as asparagine and reducing sugars, suggesting a complex reaction in NCS. Both the addition of cysteine and decreasing the $\mathrm{pH}$ were effective in suppressing the generation of acrylamide in NCS. Further studies are needed to reduce the acrylamide content of processed foods because both these approaches affect the quality of food products.

\section{References}

Adams, A., Hamdania, S., Van Lancker, F., Méjri, S., and De Kimpe, N. (2010). Stability of acrylamide in model systems and its reactivity with selected nucleophiles. J. Agric. Food Chem., 43, 1517-1522.

Baardseth, P., Blom, H., Skrede, G., Mydland, L. T., Skrede, A., and Slinde, E. (2006). Lactic acid fermentation reduces acrylamide formation and other Maillard reactions in french fries. J. Food Sci., 71, C28-C33.

Becalski, A., Brady, B., Feng, S., Gauthier, B. R., and Zhao, T. (2011). Formation of acrylamide at temperatures lower than $100{ }^{\circ} \mathrm{C}$ : the case of prunes and a model study. Food Addit. and Contam., 28, 726-730.

Becalski, A., Lau, B. P.-Y., Lewis, D., Seaman, S. W., Hayward, S., Sahagian, M., Ramesh, M., and Leclerc, Y. (2004). Arylamide in french fries: Influence of free amino acids and sugars. J. Agric. Food Chem., 52, 3801-3806.

Blank, I., Robert, F., Goldmann, T., Pollien, P., Varga, N., Devaud, S., Saucy, F., Huynh-Ba, T., and Stadler, H. (2005). Mechanisms of acrylamide formation: Maillard-induced transformation of asparagine. In "Chemistry and Safety of Acrylamide in Food," ed. by M. Friedman and D. S. Mottram. Springer, New York, Vol. 561, pp. 171-189.

Cai, Y., Zhang, Z., Jiang, S., Yu, M., Huang, C., Qiu, R., Zou, Y., Zhang, Q., Ou, S., Zhou, H., Wang, Y., Bai, W., and Li, Y. (2014). Chlorogenic acid increased acrylamide formation through promotion of HMF formation and 3-aminopropionamide deamination. $J$. Hazard. Mater., 268, 1-5.

Cheng, K.-W., Shi, J.-J., Ou, S.-Y., Wang, M., and Jiang, Y. (2010). Effect of fruit extracts on the formation of acrylamide in model reactions and fried potato crisps. J. Agric. Food Chem., 58, 309-312.

Claeys, W. L., De Vleeschouwer, K., and Hendrickx, M. F. (2005). 
Effect of amino acid on acylamide formatoin and elimination kinetics. Biotechnol. Prog., 21, 1525-1530.

Delatour, T., Périsset, A., Goldmann, T., Riediker, S., and Stadler, R. H. (2004). Improved sample preparation to determine acrylamide in difficult matrixes such as chromatography tandem mass spectroscopy. J. Agric. Food Chem., 52, 4625-4631.

De Vleeschouwer, K., Plancken, I. V., Loey, A. V., and Hendrickx, M. E. (2006). Impact of $\mathrm{pH}$ on the kinetics of acrylamide formation/ elimination reactions in model systems. J. Agric. Food Chem., 54, 7847-7855.

Ehling, S., Hengel, M., and Shibamoto, T. (2005). Formation of acylamide from lipids. In "Chemistry and safety of acrylamide in food. Advances in Experimental Medicine and Biology," ed. by M. Friedman, and D. Mottram. Springer, New York, Vol. 561, pp. 223-233.

Granda, C., Moreira, R. G., and Tichy, S. E. (2004). Reduction of acrylamide formation in potato chips by low-temperature vacuum frying. J. Food Sci., 69, E405-E411.

Granvogl, M., Magnus, J., Koehler, P., and Schieberle, P. (2004). Quantitation of 3-aminopropionamide in potatoes. A minor but potent precursor in acrylamide formation. J. Agric. Food Chem., 52, $4751-4757$.

Granvogl, M. and Schieberle, P. (2006). Thermally generated 3 -aminopropionamide as a transient intermediate in the formation of acrylamide. J. Agric. Food Chem., 54, 5933-5938.

Hirose, N., Maeda, G., Takara, K., and Wada, K. (2015). Changes in the physicochemical and flavor characteristics of the Okinawan brown sugar "Kokuto" during storage at ambient temperature. Food Preservation Science (Nihon Syokuhin Hozon Kagaku Kaishi), 41, 253-259 (in Japanese).

Ishihara, K., Matsunaga, A., Miyoshi, T., Nakamura, K., Nakayama, T., Ito, S., and Koga, H. (2005). Formation of acrylamide in a processed food model system, and examination of inhibitory conditions. $J$. Food Hyg. Soc. Japan (Shokuhin Eiseigaku Zasshi), 46, 33-39.

Jaffé, W. R. (2012). Health effects of non-centrifugal sugar (NCS): A review. Sugar Tech, 14, 87-94.

Jaffé, W. R. (2015). Nutritional and functional components of non centrifugal cane sugar: A compilation of the data from the analytical literature. J. Food Compos. Anal., 43, 194-202.

JECFA (2011). Safety evaluation of certain contaminants in food. Prepared by the 72th meeting of Joint FAO/WHO Expert Committee on Food Additives, WHO Food additives series 63. FAO JECFA monographs, 8, 1-152.

Katayama, S. and Tajima, M. (2003). "Food and Color." Kabushikigaisya Kourin, Tokyo (in Japanese).

Kim, C. T., Hwang, E.-S., and Lee, H. J. (2005). Reducing acrylamide in fried snack products by adding amino acids. J. Food Sci., 70, C354-C358.

Kobayashi, A., Gomikawa, S., Yamazaki A., Sato, S., and Konishi, T. (2014). Elimination of acrylamide by moderate heat treatment below $120^{\circ} \mathrm{C}$ with lysine and cysteine. Food Sci. Technol. Res., 20, 979-985.

Kobayashi, A., Gomikawa, S., Oguro, A., Maeda, S., Yamazaki, A.,
Sato, S., and Maekawa, H. (2019). The effect of high hydrostatic pressure on acrylamide generation in aqueous reaction systems using asparagine and glucose. Food Sci. Technol. Res., 25, 587-596.

Kukurová, K., Morales, F. J., Bednáriková, A., and Ciesarová, Z. (2009). Effect of L-asparaginase on acrylamide mitigation in a frieddough pastry model. Mol. Nutr. Food Res., 53, 1532-1539.

Mestdagh, F., Maertens, J., Cucu, T., Delporte, K., Van Peteghem, C., and De Meulenaer, B. (2008). Impact of additives to lower the formation of acrylamide in a potato model system through $\mathrm{pH}$ reduction and other mechanisms. Food Chem., 107, 26-31.

Nakasone, Y., Ikema, Y., and Kobayashi A. (1990). Changes in the composition of amino acids during manufacturing process of noncentrifugal cane sugar (Kokuto). The Science Bulletin of the Faculty of Agriculture. University of the Ryukyus, 37, 35-39 (in Japanese).

Nelson, N. (1944). A photometric adaptation of the Somogyi method for the determination of glucose. J. Biol. Chem., 153, 375-380.

Okumura, J. (1993). The Maillard reaction and flavor formation. Journal of The Brewing Society of Japan (Nihon Jyozo Kyokaishi), 88, 178-187 (in Japanese).

Palazoğlu, T. K., Savran, D., and Gökmen, V. (2010). Effect of cooking method (baking compared with frying) on acrykamide level of potato chips. J. Food Sci., 75, E25-E29.

Pedreschi, F., Kaack, K., and Granby, K. (2004). Reduction of acrylamide formation in potato slices during frying. LWT-Food Sci. Technol., 37, 679-685.

Rommens, C. M., Yan, H., Swords, K., Richael, C., and Ye, J. (2008). Low-acrylamide french fries and potato chips. Plant Biotechnol. J., 6, 843-853.

Rydberg, P., Eriksson, S., Tareke, E., Karlsson, P., Ehrenberg, L., and Törnqvist, M. (2003). Investigation of factors that influence the acrylamide content of heated foodstuffs. J. Agric. Food Chem., 51, 7012-7018.

Shimizu, S., Kakuda, H., and Makino, M. (2004). "Food and Aroma." Kabushikigaisya Kourin, Tokyo (in Japanese).

Somogyi, M. (1952). Notes on sugar determination. J. Biol. Chem., 195, 19-23.

Stadler, R. H., Robert, F., Riediker, S., Varga, N., Davidek, T., Devaud, S., Goldmann, T., Hau, J., and Blank, I. (2004). In-depth mechanistic study on the formation of acrylamide and other vinylogous compounds by the Maillard reaction. J. Agric. Food Chem., 52, 5550-5558.

Takara, K., Otsuka, K., Wada, K., Iwasaki, H., and Yamashita, M. (2007). 1,1-Diphenyl-2-picrylhydrazyl radical scavenging activity and tyrosinase inhibitory effects of constituents of sugarcane molasses. Biosci. Biotechnol. Biochem., 71, 183-191.

Tareke, E., Rydberg, P., Karlsson, P., Eriksson, S., and Törnqvist, M. (2002). Analysis of acrylamide, a carcinogen formed in heated foodstuffs. J. Agric. Food Chem., 50, 4998-5006.

Tokitomo, Y., Kobayashi, A., and Yamasishi, T. (1984). Aroma compoents of fresh sugar cane juice. Agric, Biol. Chem., 48, 2869-287.

Tsutsumiuchi, K., Hibino, M., Kambe, M., Okajima, N., Okada, M., Miwa, J., and Taniguchi, H. (2005). Effect of carbohydrates on 
formation of acrylamide in cooked food models. J. Appl. Glycosci., 52, 219-224

Yamaguchi, N. and Yamada, A. (1981). Studies on antioxidative activity of brown sugar. J. Jpn. Soc. Food Sci. Technol. (Nippon Shokuhin Kogyo Gakkaishi), 28, 303-308 (in Japanese).

Zamora, R., Delgado, R. M., and Hidalgo, F. J. (2010). Model reactions of acrylamide with selected amino compounds. J. Agric. Food Chem., 58, 1708-1713.

Zeng, X., Cheng, K.-W., Jiang, Y., Lin, Z.-X., Shi, J.-J., Ou, S.-Y., Chen, F., and Wang, M. (2009). Inhibition of acrylamide formation by vitamins in model reactions and fried potato strips. Food Chem., 116, 34-39.

Zyzak, D. V., Sanders, R. A., Stojanovic, M., Tallmadge, D. H., Eberhart, B., Ewald, D. K., Gruber, D. C., Morsch, T. R., Strothers,
M. A., Rizzi, G. P., and Villagran, M. D. (2003). Acrylamide formation mechanism in heated foods. J. Agric. Food Chem., 51, $4782-4787$.

\section{URL cited}

i) http://www.maff.go.jp/j/syouan/seisaku/acryl_amide/a_gl/ pdf/131127_acrylamide_full.pdf (Nov. 27, 2013)

ii) http://www.maff.go.jp/j/syouan/seisaku/papers_posters/pdf/106th_ eisei1.pdf (Apr. 28, 2015)

iii) http://www.pref.okinawa.jp/arc/_userdata/fukyu/2008/shido20-06. pdf (Dec. 20, 2011)

iv) http://www.maff.go.jp/j/syouan/seisaku/risk_analysis/survei/pdf/ chem_15-22.pdf (Oct. 31, 2012) 